\title{
Lower expression of Bax predicts poor clinical outcome in patients with glioma after curative resection and radiotherapy/chemotherapy
}

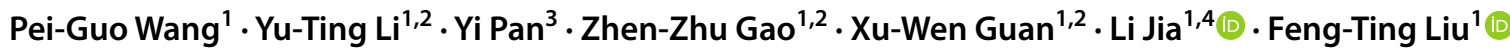

Received: 10 September 2018 / Accepted: 10 October 2018 / Published online: 16 November 2018

(c) The Author(s) 2018

\begin{abstract}
Background The prognosis in patients with gliomas after surgical resection followed by radiotherapy and/or chemotherapy is still very poor. The pro-apoptotic protein Bax, a short-lived protein in cancers, plays important roles in the sensitivity of glioma cells to spontaneous and therapy-induced apoptosis but and its prognostic value in gliomas is unknown.

Methods By an immunohistochemical method, we determined Bax protein expression from 96 patients with gliomas after curative resection. Two statistical analyses were performed to evaluate the prognostic significance of Bax protein: an independent continuous and a multivariate categorical analysis, with test/validation set-defined cut points, and Kaplan-Meier estimated outcome measures of overall survival (OS) and relapse-free survival (RFS).

Results Bax protein levels in glioblastoma were significantly decreased compared with grade II gliomas. Lower levels of Bax expression confer worse OS (continuous $P=0.025$; categorical $P=0.003$ ) and RFS (continuous $P=0.014$; categorical $P<0.0001)$ and negatively correlate with the grades of gliomas. Patients underwent radiotherapy followed by surgical resection showed significantly increased OS (median $=45$ vs. 17 months) and RFS (median $=39$ vs. 16 months). Patients with higher levels of Bax and radiotherapy showed greatly increased survival rates (median OS $=66$ months and median $\mathrm{RFS}=105$ months). Lower expression of Bax also confers inferior clinical outcome for gliomas patients after chemotherapy with temozolomide (OS and RFS P $<0.0001$ ).

Conclusion Decreased expression of Bax correlates with poor clinical outcome in patients with gliomas. We propose that Bax protein levels can be used as a reliable prognostic marker for risk-stratify patients with gliomas after curative resection and radiotherapy and/or chemotherapy.
\end{abstract}

Keywords Bax $\cdot$ Clinical outcome $\cdot$ Glioma $\cdot$ Radiotherapy $\cdot$ And chemotherapy

Pei-Guo Wang and Yu-Ting Li contributed equally to this work.

Electronic supplementary material The online version of this article (https://doi.org/10.1007/s11060-018-03031-9) contains supplementary material, which is available to authorized users.

\section{Li Jia}

1.jia@qmul.ac.uk

$\triangle$ Feng-Ting Liu

liufengting@tjmuch.com

1 Department of Radiotherapy, Key Laboratory of Cancer Prevention and Therapy, National Clinical Research Centre for Cancer, Tianjin Medical University Cancer Institute and Hospital, Tianjin's Clinical Research Center for Cancer, Tianjin 300060, China

\section{Introduction}

Gliomas are the most common type and account for $80 \%$ of all malignant primary brain tumors [1]. Under the WHO classification, gliomas are divided into four histological grades [2, 3]. The grade IV gliomas, also called glioblastoma are fast growing, the deadliest and incurable brain

2 The Graduate School, Tianjin Medical University, Tianjin 300070, China

3 Department of Pathology, Key Laboratory of Cancer Prevention and Therapy, National Clinical Research Centre for Cancer, Tianjin Medical University Cancer Institute and Hospital, Tianjin's Clinical Research Center for Cancer, Tianjin 300060, China

4 Centre for Haemato-Oncology, Barts Cancer Institute, Queen Mary University of London, London EC1M 6BQ, UK 
cancer compared with the grade I to III gliomas. Despite comprehensive treatment with surgery, radiotherapy, and chemotherapy with temozolomide (TMZ), the prognosis of glioblastoma is poor, with a median survival of 14.5-16.6 months and worse quality of life throughout the disease course $[4,5]$. The dismal prognosis conferred by glioblastoma is partly caused by the tendency to diffusely infiltrate into neighboring brain tissue, but also by the inherent resistance of these tumors to both chemotherapy and radiation [6]. However, the mechanisms by which glioblastoma are resistant to conventional therapies are poorly understood.

The Bcl-2 family of proteins plays important role in the regulation of apoptosis. Increased expression of anti-apoptotic Bcl-2 or decreased expression of pro-apoptotic Bax confers resistance of tumor cells to apoptosis in many cancers [7]. It was recently reported that combined treatment with metformin and TMZ overcomes resistance of glioblastoma cells to apoptosis by increasing the ratio of Bax/Bcl-2 [8]. Bax-deficient glioblastoma cells are highly resistance to various apoptotic stimuli compared with Bax-expressing glioblastoma cells [9]. Activation or overexpression of Bax in glioblastoma increases the sensitivity of these cells to apoptosis $[10,11]$. Several human tumor tissues, such as human pancreatic cancer [12], breast cancer [13], chronic lymphocytic leukemia [14], colorectal cancer $[15,16]$ and non-small cell lung cancer [17], have decreased expression of Bax protein which is significantly associated with poor clinical outcomes of these cancers. It has been proposed that modulation of Bax expression may be a useful therapeutic modality for gliomas [11, 18].

Bax is a short-lived protein in cancer cells and its degradation is ubiquitin/proteasome-dependent $[14,19]$. We previously reported that increased Bax degradation activity is associated with worse clinical outcome in human chronic lymphocytic leukemia [14]. The levels of Bax protein expression in human gliomas tissue and its impact on the clinical outcomes in patients with gliomas are highly controversy due to limited case numbers [9, 20-23]. It was recently reported that the intratumoral administration of proteasome inhibitor bortezomib into the cranial cavity significantly increased survival rate of glioma-bearing mice [24], suggesting that the ubiquitin/proteasome system plays an important role in the disease progression of gliomas.

In this study, we aimed to determine whether levels of Bax protein expression have impact on clinical outcomes in 50 patients with glioblastoma and 46 patients with grade II or III gliomas. The levels of Bax mRNA and protein expression in glioblastoma and normal brain were analyzed to explore the effect of Bax instability in patients with glioblastoma. We also provide clinical data of the impact of Bax levels on the efficacy of radiotherapy and chemotherapy in patients with gliomas.

\section{Materials and methods}

\section{Patients and samples}

Formalin-fixed, paraffin-embedded gliomas tissue specimens were randomly selected from the archives of the Department of Pathology of the Tianjin Medical University Cancer Institute and Hospital (Tianjin, China). Samples used were from 96 glioma patients, who underwent initial surgical resection between December 2006 and September 2016 in Tianjin Cancer Hospital. Ethical approval for this study was obtained from the local ethics committee. Patients gave verbal consent for the use of their tumor tissues for future investigations, which had been performed for many years at time of the initial diagnosis. All specimens were handled and made anonymous according to ethical and legal standards. None of the patients had received radiotherapy or chemotherapy prior to surgery. The patient demographics and clinical characteristics are summarized in Supplementary Table 1. The diagnosis of these glioma samples was verified by two senior pathologists according to the 2016 WHO classification of tumors of the central nervous system [2,3]. Detailed pathologic and clinical data were collected for all samples, including the WHO grade. This cohort includes 50 WHO IV, 24 WHO III and 22 WHO II glioma patients. The median follow-up time for overall survival (OS) and relapse-free survival (RFS) were 28 and 22.6 months, respectively (Supplementary Fig. 1; Supplementary Tables 1 and 2). In addition, 21 normal brain control tissues were obtained from patients who underwent surgery for non-neoplastic tissues adjacent to the tumor. Comparison of Bax mRNA expression levels between normal brain $(n=10)$ and glioblastoma ( $\mathrm{n}=542$ cases) was obtained from The Cancer Genome Atlas (TCGA) brain dataset, Oncomine (https:// www.oncomine.org/). Two datasets $(n=206$, and $n=151$ cases, respectively) for analyzing the association of Bax mRNA levels with clinical outcomes in patients with multiform glioblastoma were obtained from TCGA database $[25,26]$.

\section{Follow-up and primary endpoints}

A repeat tumor-imaging study was performed approximately 3 months after resection or completion of radiotherapy. Postoperative patients were followed-up periodically to exclude relapse of glioma. Update inquiries about current survival status of all patients were made by telephone calls periodically by the end of April 2017. Recurrence or progression was declared mainly on the basis of magnetic resonance imaging (MRI), the second postoperative 
pathologic reports according to the WHO guidelines, and the comprehensive diagnosis of Multidisciplinary Team (MDT). Team doctors from departments of neurosurgery, pathology, radiology and radiobiology working together to diagnose relapse according to the Response Assessment in Neuro-Oncology Criteria (RANO) to exclude pseudoprogression $[27,28]$. The co-primary endpoints were the duration of OS from randomization, which was defined as the diagnosis time until death from any cause, and the duration of RFS, which was defined as the diagnosis time until either disease progression or death [4].

\section{Immunohistochemistry (IHC)}

Glioma specimens were formalin fixed, paraffin embedded and sectioned ( $5 \mu \mathrm{m}$ in thickness). The slides were de-paraffinized in xylene and rehydrated through graded ethanol to water before staining. All sections were treated with $5 \mathrm{mM}$ citrate buffer ( $\mathrm{pH} \mathrm{6.0)}$ ) for antigen retrieval and with 3\% $\mathrm{H}_{2} \mathrm{O}_{2}$ for the inactivation of endogenous peroxidase. After blocking for $30 \mathrm{~min}$, sections were incubated with a mouse anti-Bax antibody (Santa Cruz Biotechnology, sc-7480, 1:200 dilution) overnight at $4{ }^{\circ} \mathrm{C}$. After wash, the sections were stained with a secondary antibody for $30 \mathrm{~min}$ at room temperature. Diaminobenzidine and hematoxylin were used as a chromogen substrate and for nuclear counterstaining, respectively [29].

\section{Evaluation by IHC}

The whole tissue fields $(\times 400$ and $\times 200)$ were examined under a light microscope. Immunoreactivity for Bax proteins was scored by evaluating the number of positive tumor cells over the total number of tumor cells, the intensity of tumor cells was scored according to morphological criteria. Scores were assigned by using $5 \%$ increments $(0 \%, 5 \%, 10 \%$ ...100\%). Expression for Bax was independently assessed by two pathologists, who were blinded to the clinicopathological data. Their conclusions agreed in approximately $90 \%$ of the cases, indicating that this scoring method is highly reproducible. If two assessments were consistent with the results they scored, the value was selected. In cases where completely different results occurred, the appropriate score was further discussed and agreed by two assessors.

\section{Statistical analysis}

Statistical analysis was performed using IBM SPSS version 19.0 for Windows and GraphPad Prism version 5.01. To increase the robustness of statistical inferences, two independent analyses were performed: categorical and continuous data analysis. The categorical data analysis was a clinically applicable method, dividing patients categorically into two groups on the basis of levels of Bax expression (high and low). Categorical (cut point) data analysis was performed using the X-tile statistical package (Yale University, New Haven, CT, USA) [30]. X-Tile divides the cohort into two independent data sets (a test set and a validation set) in a 1:2 ratio, determines optimal cut points for each marker for the test set, and applies this to the validation set [29,31]. The continuous data analysis was performed as continuous variables by using Cox regression analysis to value the prognostic effect of the biomarker.

Both unpaired $t$ test and analysis of variance (ANOVA) test were performed for group comparisons, and correlations between two variables were evaluated using Spearman's rank correlation test. The chi-squared test is used to determine whether there is a significant difference between the expected frequencies and the observed frequencies in Bax expression and other more categories risk factors.

Kaplan-Meier curves defined by the cut points were generated, according to the $\mathrm{P}$ values, hazard ratio (HR) and 95\% confidence interval (CI) determined by log-rank test. Univariate analyses were performed first, including one factor a time to examine their prognostic effects. Multivariate analysis was performed using a Cox proportional hazards model to define the independent effect of prognostic variable. Relevant factors were considered simultaneously through the use of enter stepwise models. After the continuous and categorical variables were adjusted, the confounding effect between two risk factors were calculated. The estimated measures of univariate analysis before $\left(\mathrm{HR}_{\text {crude }}\right)$ and multivariate analysis after adjusting $\left(\mathrm{HR}_{\text {adjusted }}\right)$ for confounding were calculated as: magnitude of confounding $=\left(\mathrm{HR}_{\text {crude }}-\mathrm{HR}_{\text {adjusted }}\right) /$ $\mathrm{HR}_{\text {crude }} \times 100 \%$. If the difference between the two measures of association is $10 \%$ or more, then confounding was present [29] (http://sphweb.bumc.bu.edu). All P values less than 0.05 were considered statistically significant. *,** and *** indicate $\mathrm{P}$ value $<0.05,0.01$ and 0.001 , respectively [29, 32].

\section{Results}

\section{Bax protein expression is significantly decreased in glioblastoma compared with low grade gliomas}

Upregulation and activation of Bax is a crucial step for treatment-induced apoptosis in glioblastoma [10, 11, 33]. However, Bax expression status in human glioma is still elusive. To compare the levels of Bax in different grade of gliomas, expression of Bax protein was determined in 96 gliomas and 21 normal brain control tissues using IHC. Bax expression was detected in both glioma and normal brain tissues (Fig. 1a). The levels of Bax were expressed as \% of Bax positive cells. Bax expression in glioma samples displayed 

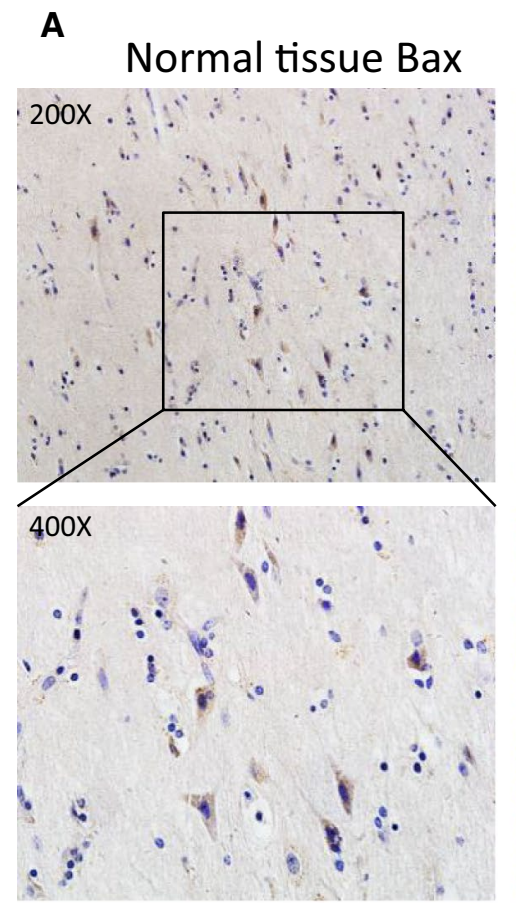

B

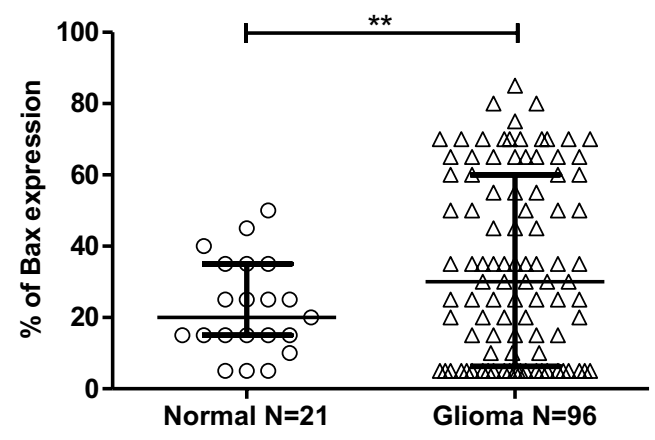

GBM Bax-Low

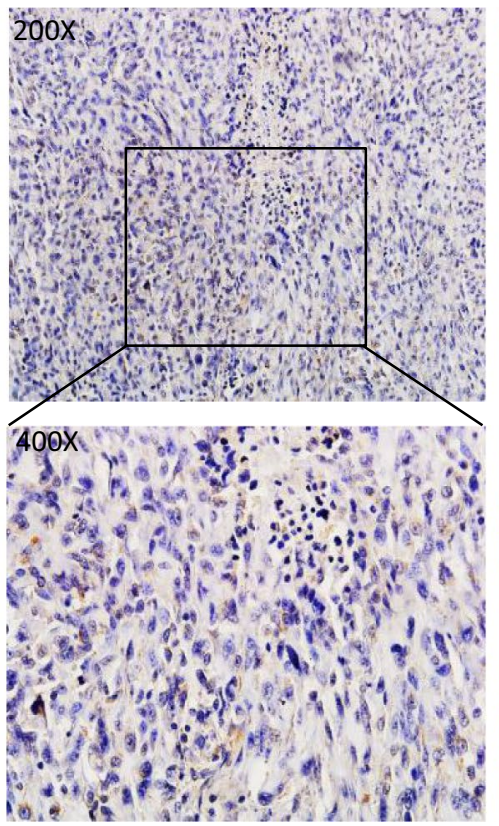

Glioma Bax-High

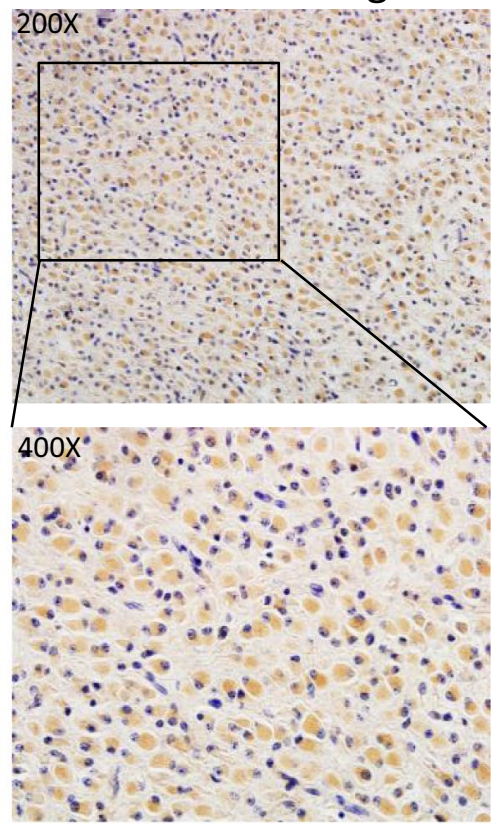

D
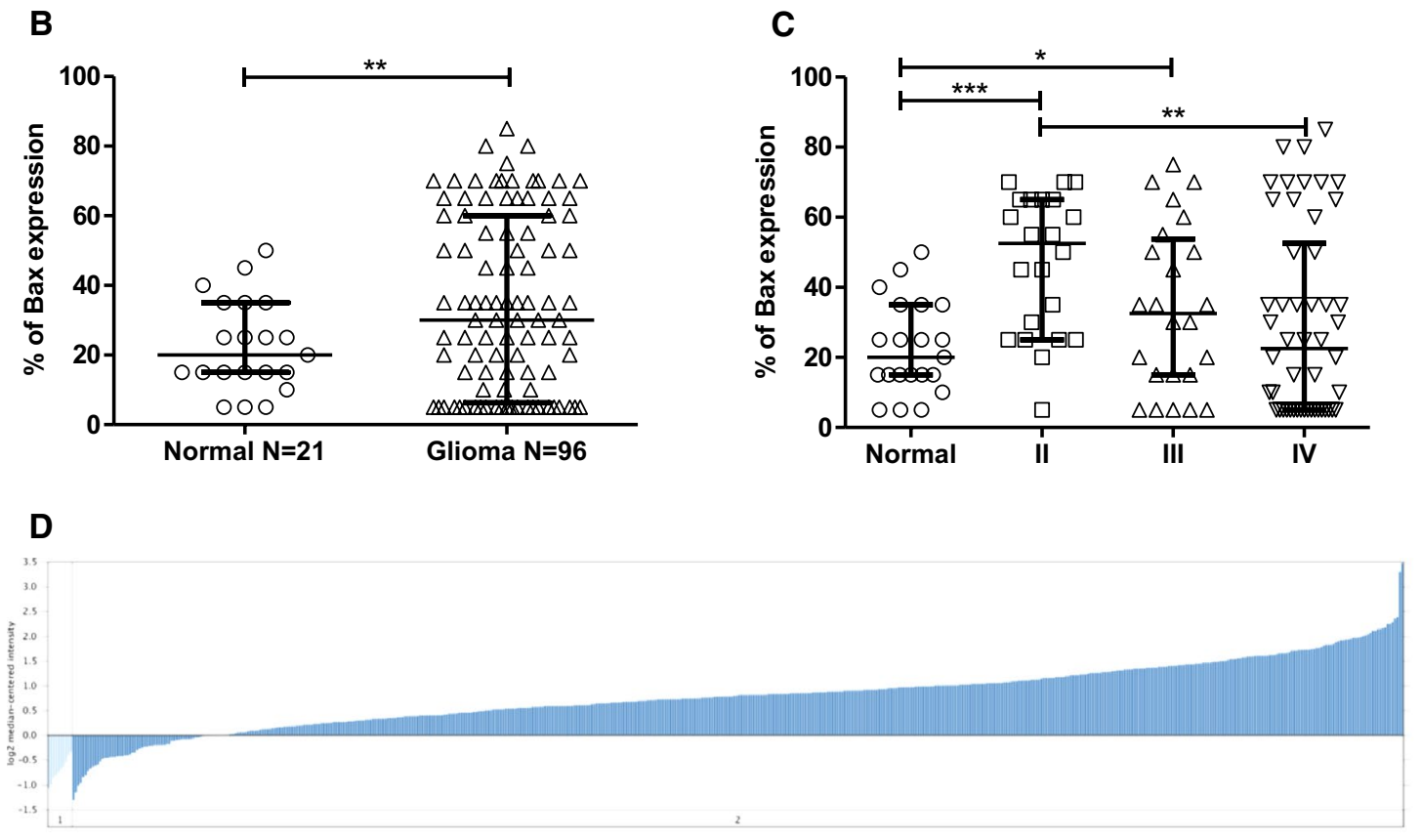

Fig. 1 Comparison of levels of Bax protein and Bax mRNA expression in glioma specimens. a Representative examples of control, low and high expression of Bax protein expression in Gliomas. Bax expression is shown by horseradish peroxidase-diaminobenzidine (HRP-DAB) immunostaining. b The levels of Bax protein expression were presented as $\%$ of Bax positive cells. Data presented are medians with interquartile ranges. c Data presented are medians of Bax protein expression with interquartile ranges: $52.5 \%(25-65 \%)$ for WHO II grade, $32.5 \%$ (15-55\%) for WHO III grade and $22.5 \%$ (5-50\%) for WHO IV grade glioma tissues. The significant difference in Bax protein expression between glioma and normal brain tissues were analysed using unpaired $t$ test. d Bax mRNA levels in 10 normal Brain tissues and 542 GBM tissues were performed by TCGA brain statistics from http://www.oncomine.org. The P value $(1.39 \mathrm{E}-10)$ of Bax mRNA levels between normal and GBM are significantly different 
a heterogeneous expression pattern and the median levels $(35 \%)$ were significantly higher than in the non-malignant normal controls $(23 \%$; $\mathrm{P}<0.01$; Fig. 1b). Further stratification showed that the grade II and III glioma have significantly increased Bax expression compared with the control $(\mathrm{P}<0.001 ; \mathrm{P}<0.05 ;$ Fig. 1c). However, the grade IV (glioblastoma) showed significantly decreased Bax protein expression compared with the grade II tumors $(29.70 \pm 3.76$ vs. $46.82 \pm 4.22$; $\mathrm{P}<0.01$; Fig. 1c). Bax mRNA levels in glioblastoma are significantly greater than in the normal brain control tissues (Fig. 1d). However, our data showed that Bax protein levels in glioblastoma was not higher than the control. These results demonstrate that Bax protein expression increases in the early stage of glioma but decreases with disease progression towards the late stage. This may be, at least partly, due to increased Bax degradation activity in glioblastoma.

\section{Continuous data analysis for the prognostic significance of Bax protein levels in patients with gliomas}

The prognostic significance of Bax on the clinical outcomes in glioma patients was first determined using continuous data analysis and compared with other risk factors. Bax expression showed significant impact on OS $(\mathrm{P}=0.025$; $\mathrm{HR}=0.987)$ and RFS $(\mathrm{P}=0.014 ; \mathrm{HR}=0.984)$. Other risk factors (continuous variables), such as age and WHO grade also showed prognostic significance on OS and RFS (Table 1). Not surprising, the hazard ratios (HRs) of both age and WHO grade were higher than 1, meaning older age or higher WHO grade patients had higher risk. However, HRs of Bax in both OS and RFS were lower than 1, indicating that lower levels of Bax were associated with poor prognosis. For determining whether Bax was an independent prognostic marker, multivariate analysis was then conducted by combination of Bax with age and WHO grade. The HRs of Bax still remained lower than 1, indicating Bax was an independent prognostic marker for patients with glioma. Although the confounding effect exists between WHO grade and other factors, the prognostic significance of WHO grade on both OS and RFS retained after adjusting (Table 1 and Supplementary Table 3). These results demonstrate that Bax as well as WHO grade are independent prognostic biomarkers for predicting the clinical outcomes in patients with gliomas.

\section{Categorical data analysis for the prognostic significance of Bax protein levels in patients with gliomas}

We next used categorical data analysis to determine the association between Bax levels and clinical outcomes. Two variables with low and high expression of Bax were defined using the X-Tile software to generate cut points for each outcome. Age was categorized by median age. WHO grades were categorized as grade II, III and IV groups. The radiotherapy or chemotherapy for patients were also categorized as with (Yes) or without (No) groups (Table 2 and Supplementary Table 4). Chi square distribution analysis showed that $95.5 \%$ grade II, $79.2 \%$ grade III and $58.2 \%$ grade IV glioma patients express higher Bax in $(\mathrm{P}<0.003)$ and $68.8 \%$ relapsed patients vs. $94.4 \%$ nonrelapsed patients express higher $\mathrm{Bax}(\mathrm{P}<0.027)$. Interestingly, $82.5 \%$ tumors in the frontal lobe express higher Bax vs. $57.1 \%$ tumors vs. in the temporal lobe $(\mathrm{P}<0.032$ and Supplementary Table 4). Log rank analysis showed that higher expression of Bax was significantly associated longer OS with median OS for $\mathrm{Bax}^{\mathrm{HIGH}}=44.62$ and $\mathrm{Bax}^{\mathrm{LOW}}=16.95$ months $(\mathrm{P}=0.0003 ; \mathrm{HR}=0.365)$ and longer RFS with median RFS for $\mathrm{Bax}^{\mathrm{HIGH}}=50.43$ and $\mathrm{Bax}^{\mathrm{LOW}}=8.8$ months $(\mathrm{P}<0.0001 ; \mathrm{HR}=0.312)($ Table 2$)$. Other categorical risk factors, such as age, gender (female vs. male), tumor numbers (multiple vs. single), tumor location (temporal vs. frontal), relapse (yes vs. no), WHO grade (IV vs. III vs. II) all showed prognostic significance on both OS and RFS (Table 2; Supplementary Figs. 2, 3 and 4). Bax mRNA expression in glioblastoma and clinical outcomes of two independent cohorts $[25,26]$ was analyzed retrospectively (online accessible TCGA database). The levels of low and high mRNA of Bax were also defined by the X-Tile software to generate cut-off points
Table 1 Uni- and multivariate analysis of continuous covariates of OS and RFS

\begin{tabular}{|c|c|c|c|c|c|}
\hline \multirow[t]{2}{*}{ Outcome } & \multirow[t]{2}{*}{ Covariates } & \multicolumn{2}{|l|}{ Univariate analysis } & \multicolumn{2}{|l|}{ Multivariate analysis } \\
\hline & & HR $(95 \%$ CI $)$ & $P$ & HR $(95 \% \mathrm{CI})$ & $P$ \\
\hline \multirow[t]{3}{*}{ OS } & Bax & $0.987(0.975-0.998)$ & 0.025 & $0.992(0.982-1.003)$ & 0.160 \\
\hline & Age & $1.026(1.007-1.046)$ & 0.009 & $1.013(0.991-1.036)$ & 0.263 \\
\hline & WHO Grade & $2.765(1.802-4.241)$ & $<0.0001$ & $2.476(1.577-3.886)$ & $<0.0001$ \\
\hline \multirow[t]{3}{*}{ RFS } & Bax & $0.984(0.971-0.997)$ & 0.014 & $0.991(0.979-1.003)$ & 0.127 \\
\hline & Age & $1.030(1.008-1.053)$ & 0.008 & $1.021(0.995-1.049)$ & 0.115 \\
\hline & WHO Grade & $3.670(2.205-6.109)$ & $<0.0001$ & $3.288(1.947-5.553)$ & $<0.0001$ \\
\hline
\end{tabular}

Covariates that were included in the multivariate analysis were selected using the Enter stepwise 
Table 2 Uni- and multi-variate analysis of categorical covariates of OS and RFS

\begin{tabular}{|c|c|c|c|c|c|c|}
\hline \multirow[t]{2}{*}{ Outcome } & \multirow[t]{2}{*}{ Covariates (cut points) } & \multirow[t]{2}{*}{ OS months ${ }^{\mathrm{a}}$} & \multicolumn{2}{|l|}{ Univariate analysis } & \multicolumn{2}{|l|}{ Multivariate analysis } \\
\hline & & & HR $(95 \%$ CI $)$ & $P$ & HR $(95 \% \mathrm{CI})$ & $P$ \\
\hline \multirow[t]{9}{*}{ OS } & $\operatorname{Bax}^{\mathrm{b}}(>10$ vs. $\leq 10)$ & $45: 17$ & $0.403(0.220-0.739)$ & 0.0024 & $0.474(0.176-1.277)$ & 0.140 \\
\hline & $\operatorname{Age}^{c}(>53$ vs. $\leq 53)$ & $20: 45$ & $1.785(1.031-3.089)$ & 0.039 & $1.208(0.512-2.848)$ & 0.666 \\
\hline & Gender (female vs. male) & $23: 66$ & $2.001(1.148-3.490)$ & 0.014 & $1.479(0.648-3.374)$ & 0.352 \\
\hline & Tumor number (multiple vs. single) & $17: 36$ & $1.673(0.934-2.997)$ & 0.083 & $0.858(0.333-2.207)$ & 0.750 \\
\hline & Tumor location (temporal vs. frontal) & 19:111 & $2.440(1.212-4.911)$ & 0.012 & $0.639(0.243-1.682)$ & 0.365 \\
\hline & Relapse (yes vs. no) & 25:- & $37.807(2.251-635.0)$ & 0.012 & $219975(0-2.91 \mathrm{E} 154)$ & 0.944 \\
\hline & Radiotherapy (yes vs. no) & $45: 17$ & $0.431(0.246-0.755)$ & 0.0003 & $0.409(0.166-1.007)$ & 0.052 \\
\hline & Chemotherapy (yes vs. no) & $28: 21$ & $0.801(0.433-1.480)$ & 0.479 & $0.661(0.228-1.917)$ & 0.446 \\
\hline & WHO grade (IV vs. III vs. II) & $17: 36: 112$ & $2.765(1.802-4.241)$ & $<0.0001$ & $2.861(1.396-5.864)$ & 0.004 \\
\hline \multirow[t]{9}{*}{ RFS } & $\operatorname{Bax}^{\mathrm{b}}(>15$ vs. $\leq 15)$ & $50: 9$ & $0.312(0.162-0.601)$ & $<0.0001$ & $0.506(0.192-1.338)$ & 0.170 \\
\hline & $\operatorname{Age}^{c}(>53$ vs. $\leq 53)$ & $12: 33$ & $1.838(1.002-3.373)$ & 0.049 & $1.258(0.514-3.078)$ & 0.614 \\
\hline & Gender (female vs. male) & $16: 50$ & $2.041(1.116-3.732)$ & 0.021 & $1.451(0.635-3.315)$ & 0.377 \\
\hline & Tumor number (multiple vs. single) & $12: 33$ & $1.896(0.994-3.619)$ & 0.052 & $0.891(0.345-2.304)$ & 0.812 \\
\hline & Tumor location (temporal vs. frontal) & $10: 50$ & $3.090(1.392-6.855)$ & 0.006 & $0.702(0.278-1.773)$ & 0.454 \\
\hline & Relapse (yes vs. no) & 13:- & $47.505(3.230-698.6)$ & 0.005 & $200877(0-3.14 \mathrm{E} 150)$ & 0.943 \\
\hline & Radiotherapy (yes vs. no) & $39: 16$ & $0.487(0.263-0.904)$ & 0.023 & $0.401(0.161-0.996)$ & 0.049 \\
\hline & Chemotherapy (yes vs. no) & $18: 50$ & $1.367(0.632-2.959)$ & 0.427 & $0.618(0.210-1.814)$ & 0.381 \\
\hline & WHO grade (IV vs. III vs. II) & $8: 29: 105$ & $3.670(2.205-6.109)$ & $<0.0001$ & $2.894(1397-5.992)$ & 0.004 \\
\hline
\end{tabular}

Covariates that were included in the multivariate analysis were first selected using the Enter stepwise

${ }^{a}$ Median survival rate (months)

${ }^{\mathrm{b}}$ Categorical cut-off points were defined by the X-tile software

${ }^{\mathrm{c}}$ Median age

for each outcome. Bax mRNA levels in glioblastoma patients from two datasets did not show any prognostic significance on both OS and RFS (Supplementary Fig. 5; Supplementary Table 5). Similarly, Bax protein levels in glioblastoma patients from our data did not show statistical significance on OS and RFS (Supplementary Fig. 6; Supplementary Table 6). However, the median RFS time in Bax lower expression group was shorter than the higher group (6.4 vs. 10.2 months). These results indicate that lower expression of Bax protein (mainly in glioblastoma) but not Bax mRNA is significantly associated with poor prognosis in patients with gliomas.

For determining the confounding effect of Bax with other categorical risk factors, Cox regression analysis was then conducted by combination of Bax with multivariable (risk factors) (Table 2). After Bax was adjusted with other prognostic markers, the HRs remained less than one, suggesting no confounding effects between Bax expression and other risk factors. However, Bax levels on prognosis were no longer significant (Table 2). This was due to lower but not higher Bax expression was significantly associated with higher chances of relapse, without radiotherapy and higher grade of glioma. These results further demonstrate that lower levels of Bax protein expression is significantly associated with relapse, higher WHO grade, and shorter survival rates in patients with glioma.

\section{Higher level of Bax is significantly associated with longer survival rates in glioma patients underwent radiotherapy and/or chemotherapy}

Curative resection, radiotherapy and concomitant chemotherapy with TMZ is the standard treatment approach for glioma patients [34-36]. In this cohort, patients underwent radiotherapy have significantly better clinical outcomes OS $(\mathrm{P}=0.003, \mathrm{HR}=0.431)$ and $\mathrm{RFS}(\mathrm{P}=0.023, \mathrm{HR}=0.487)$, determined using Cox regression analysis (Table 2). Kaplan-Meier curves show that the patients completed radiotherapy had a significantly longer OS and RFS compared with the patients had not undergone or completed radiotherapy (Fig. 2a, b). The median OS rate for patients with radiotherapy is 44.62 months vs. 16.95 months for patients without radiotherapy and the median RFS rate for patient with radiotherapy is 39.36 months vs. 15.97 months for patients without radiotherapy. However, patients treated with or without TMZ did not show statistical differences on both OS and RFS (Fig. 2c, d). 
A
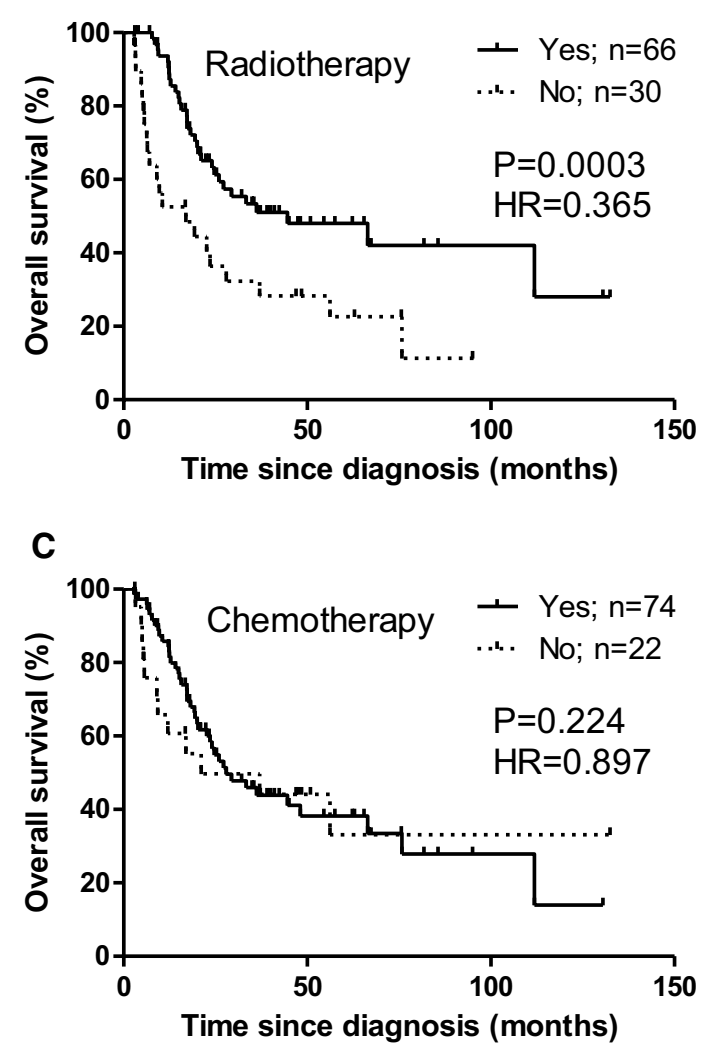

Fig. 2 Prognostic effects of radiotherapy (a, b) or chemotherapy (c, d) on patients with glioma. Kaplan-Meier survival curves of glioma patients according to with or without radiotherapy or chemotherapy were generated with GraphPad Prism program. a OS of glioma patients was based on Yes and No. b RFS of glioma patients was based on Yes and No. a, b 'Yes': the patients had completed the radiotherapy with or without chemotherapy. 'No': the patients had

As shown above, Bax protein expression and radiotherapy both are independent risk factors for gliomas (Table 2). We then further determined the association between Bax expression and radiotherapy or chemotherapy on clinical outcomes in patients with gliomas. We combined Bax expression and radiotherapy variables and categorized them into four subgroups: i.e., $\mathrm{Bax}^{\mathrm{HIGH}} / \mathrm{RT}^{+}, \mathrm{Bax}^{\mathrm{LOW}} / \mathrm{RT}^{+}, \mathrm{Bax}^{\mathrm{HIGH}} / \mathrm{RT}^{-}$and $\mathrm{Bax}{ }^{\mathrm{LOW} /}$ $\mathrm{RT}^{-}$(Fig. 3a-d). The prognostic significance of these subgroups was evaluated by Log-rank (Mantel Cox) test. The $\mathrm{Bax}^{\mathrm{HIGH}} / \mathrm{RT}^{+}$subgroup showed longer survival rates for both OS $(\mathrm{P}=0.0143, \mathrm{HR}=0.2984)$ and RFS $(\mathrm{P}=0.0143$, $\mathrm{HR}=0.2684$ ) when compared with the $\mathrm{Bax}^{\mathrm{LOW}} / \mathrm{RT}^{+}$subgroup. Most strikingly, the median OS rate for $\mathrm{Bax}^{\mathrm{HIGH} /}$ $\mathrm{RT}^{+}$is 66.43 months vs. Bax ${ }^{\mathrm{LOW}} / \mathrm{RT}^{+}$is 17.25 months. The median RFS rate for $\mathrm{Bax}^{\mathrm{HIGH}} / \mathrm{RT}^{+}$is 105.1 months vs. 11.99 months for $\mathrm{Bax}^{\mathrm{LOW}} / \mathrm{RT}^{+}$group. By comparison with above analyzed results on radiotherapy alone, the risk factor $\mathrm{HR}$ reduced from $\mathrm{HR}=0.431\left(\mathrm{RT}^{+}\right)$to $\mathrm{HR}=0.298$
B
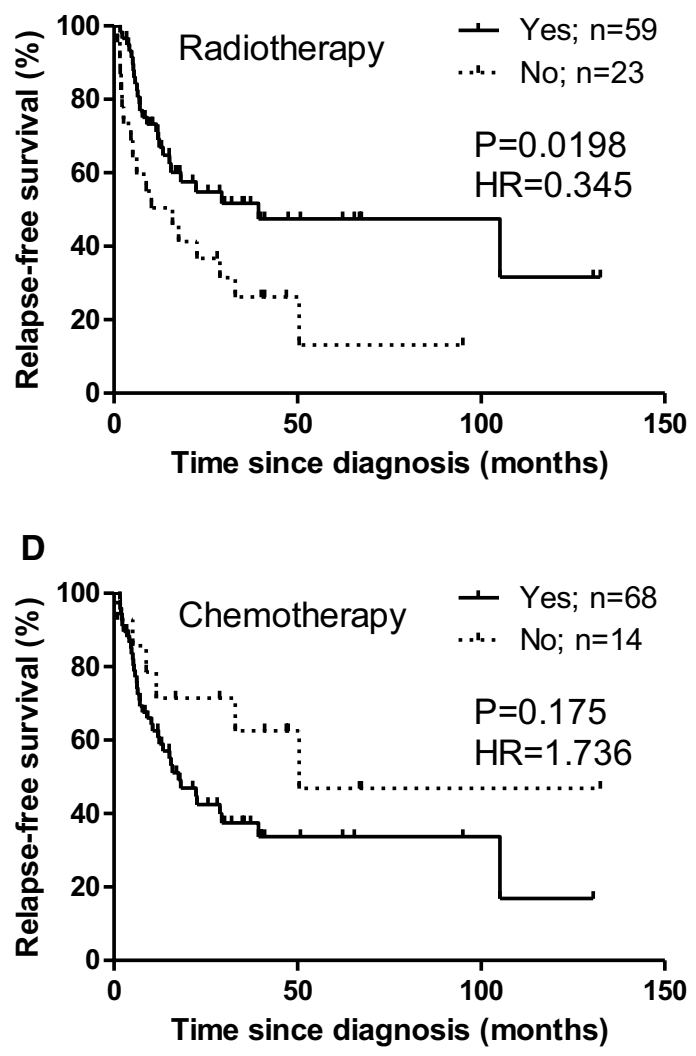

not undergone or completed the radiotherapy with or without chemotherapy. c OS of glioma patients was based on Yes and No. d RFS of glioma patients was based on Yes and No. c, $\mathbf{d}$ 'Yes': the patients had chemotherapy with TMZ with or without radiotherapy. 'No': the patients had not undergone chemotherapy with or without radiotherapy. 'n': numbers of patients

$\left(\mathrm{Bax}^{\mathrm{HIGH}} / \mathrm{RT}^{+}\right)$for $\mathrm{OS}$ and from HR $=0.487\left(\mathrm{RT}^{+}\right)$to $\mathrm{HR}=0.268\left(\mathrm{Bax}^{\mathrm{HIGH}} / \mathrm{RT}^{+}\right)$for RFS. The median OS rate increased from $44.62\left(\mathrm{RT}^{+}\right)$to 66.43 months and median RFS increased from 39.36 months $\left(\mathrm{RT}^{+}\right.$) to 105.1 months $\left(\mathrm{Bax}^{\mathrm{HIGH}} / \mathrm{RT}^{+}\right)$. This indicates that the levels of $\mathrm{Bax}$ protein have a great impact on the clinical outcome in patients underwent radiotherapy. The $\mathrm{Bax}^{\mathrm{HIGH}} / \mathrm{RT}^{-}$subgroup showed significantly longer survival rates for RFS $(\mathrm{P}=0.0148, \mathrm{HR}=0.2339)$ but not statistically significant for OS $(\mathrm{P}=0.0754, \mathrm{HR}=0.3519)$ when compared with the $\mathrm{Bax}^{\mathrm{LOW}} / \mathrm{RT}^{-}$subgroup. Although the patients underwent radiotherapy have significantly improved clinical outcomes (Fig. 2; Table 2), the patients with higher Bax without radiotherapy $\left(\mathrm{Bax}^{\mathrm{HIGH}} / \mathrm{RT}^{-}\right.$) have longer OS and RFS compared with patients with lower $\mathrm{Bax}^{\mathrm{LOW}} / \mathrm{RT}^{+}$subgroup (23.5 vs. 17.3 months) and (25.4 vs. 12 months), respectively (Table 2). This indicates that higher expression of Bax predicts longer time to recurrences of glioma patients without radiotherapy. 

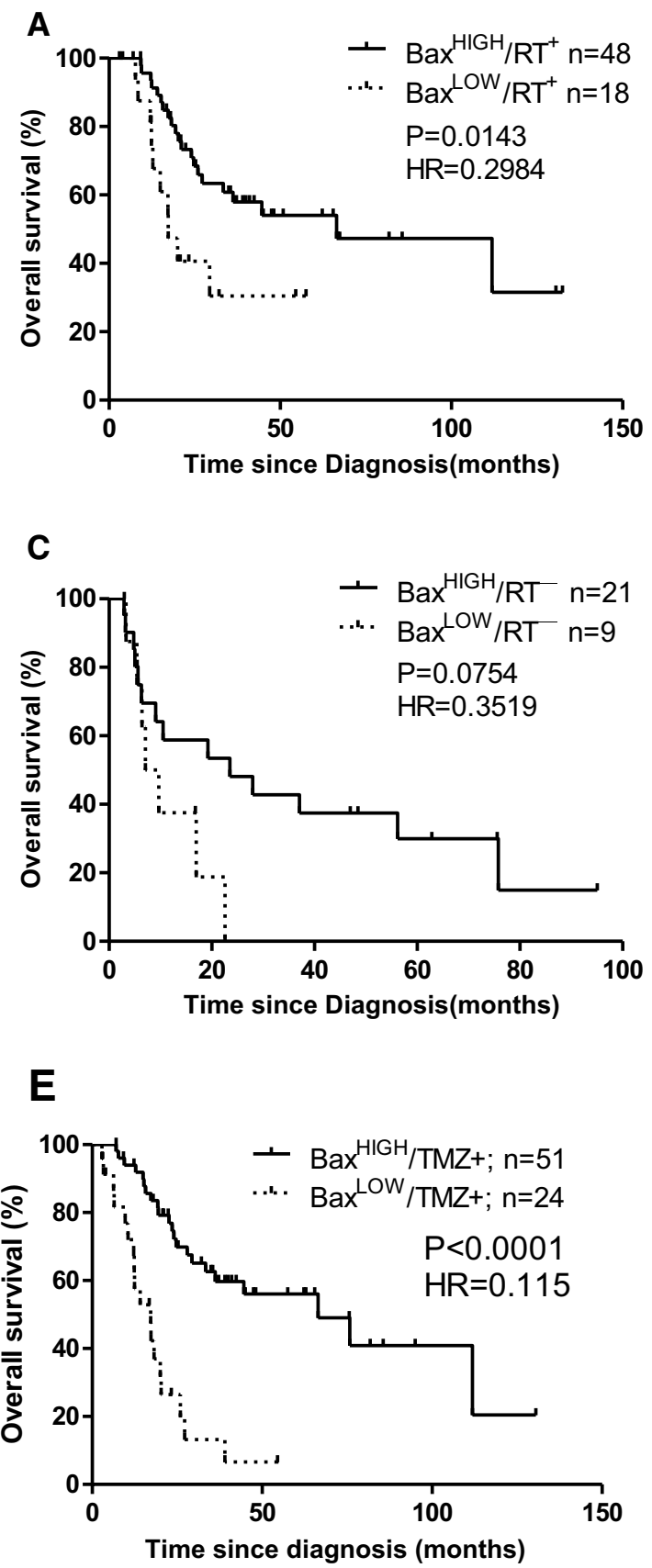

Fig. 3 Association between Bax expression and radiotherapy/ chemotherapy in clinical outcomes in patients with gliomas. a, c Overall survival for patients with or without radiotherapy. Two subgroups were defined according to the cut-off point for Bax (10\%) and whether the patients had finished the radiotherapy: $\mathrm{Bax}^{\mathrm{HIGH} /}$ $\mathrm{RT}^{+}=\mathrm{Bax}>10 \%$ and the patients had completed the radiotherapy; $\mathrm{Bax}^{\mathrm{LOW}} / \mathrm{RT}^{-}=\mathrm{Bax} \leq 10 \%$ and the patients had not underwent or completed the radiotherapy. b, d Relapse-free survival for patients with or without radiotherapy. Four subgroups were defined according to the cut-off point for Bax (15\%) and whether the patients had

Totally 75 patients received chemotherapy (with TMZ) together with or without radiotherapy after curative resection. The patients with lower Bax expression showed
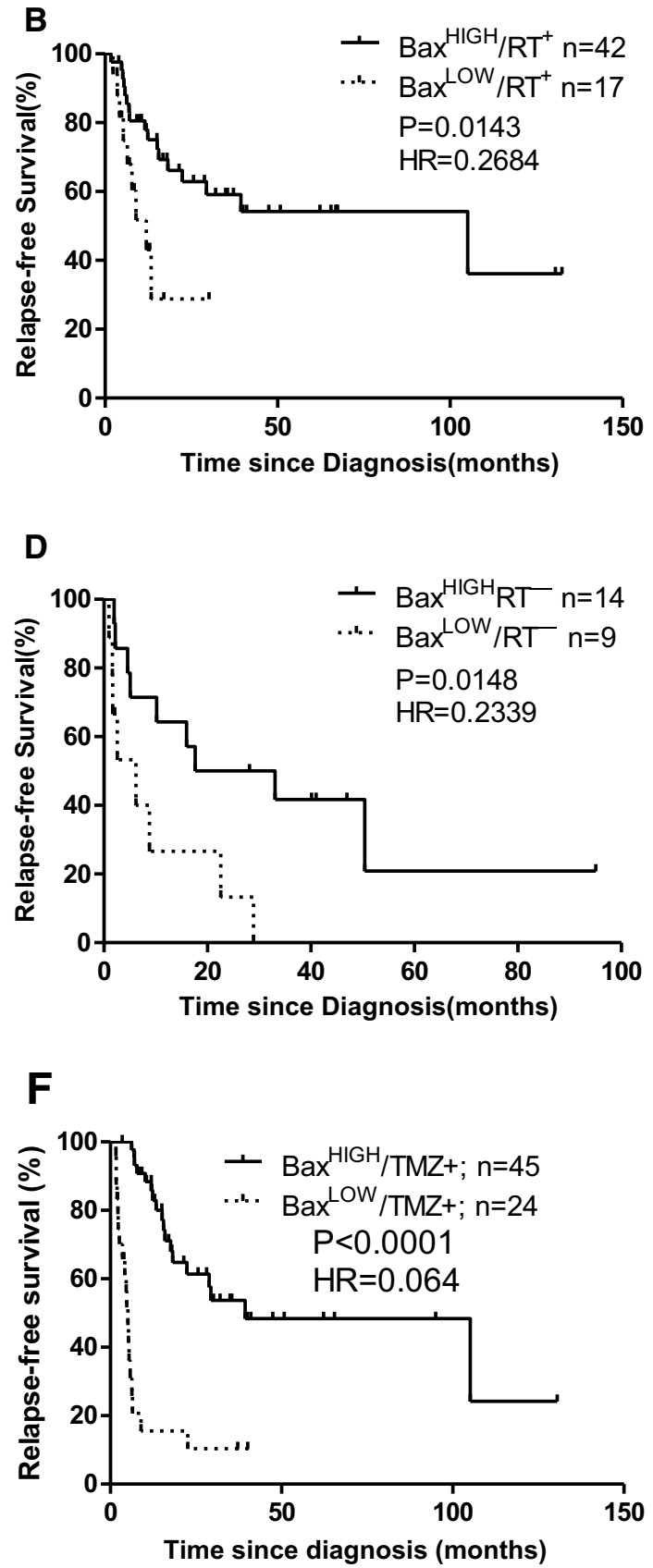

finished the radiotherapy: $\mathrm{Bax}^{\mathrm{HIGH}} / \mathrm{RT}^{+}=\mathrm{Bax}>15 \%$ and the patients had finished the radiotherapy; $\mathrm{Bax}^{\mathrm{LOW}} / \mathrm{RT}^{-}=\mathrm{Bax} \leq 15 \%$ and the patients had not finished the radiotherapy. e Overall survival for patients underwent chemotherapy. The $\mathrm{Bax}^{\mathrm{HIGH}}$ and $\mathrm{Bax}^{\mathrm{LOW}}$ groups for OS were defined according to the cut-off point for Bax (10\%). f Relapse-free survival for patients underwent chemotherapy. The $\mathrm{Bax}^{\mathrm{HIGH}}$ and $\mathrm{Bax}{ }^{\mathrm{LOW}}$ groups for RFS were defined according to the cut-off point for Bax (15\%). Cut points were generated by the X-Tile software. 'n': numbers of patients. TMZ indicates temozolomide

significantly decreased $\mathrm{OS}(\mathrm{P}<0.0001, \mathrm{HR}=0.115)$ and RFS $(\mathrm{P}<0.0001, \mathrm{HR}=0.064)$ (Fig. 3e, f). These results demonstrate that lower expression of Bax protein is 
associated with worse clinical outcome in glioma patients after radiotherapy and/or chemotherapy. Combination of Bax expression levels with radiotherapy or chemotherapy is a potent prognostic predictor of clinical outcome in patients with glioma.

\section{Discussion}

The molecular basis of glioma patients with long-term survival has not been fully defined. In this study, we demonstrate that glioblastoma has decreased levels of Bax protein compared with low grade glioma. Lower Bax protein expression confers a worse clinical outcome in patients with gliomas after surgical resection and radiotherapy/chemotherapy.

Decreased Bax protein levels are associated with worse clinical outcomes in many cancers due to its pro-apoptotic function [14, 37-39]. In cancer cells, Bax is a short-lived protein and its protein levels are not consistent with the levels of mRNA [14, 19]. Lost p53 transcriptional activity in glioma tumor is also associated with decreased Bax protein expression [23]. Our results showed that Bax protein expression is lower in glioblastoma compared with grade II glioma which has an increased Bax expression than normal brain tissue. However, it is unclear why and how low-grade gliomas have increased Bax expression compared with the normal control. Based on our retrospective analysis, Bax mRNA levels in glioblastoma are significantly higher than those in normal samples. Because no available online data on Bax mRNA in low grade gliomas, we are not able to evaluate Bax mRNA levels in these tumors. The precise mechanism of decreased Bax protein levels in glioblastoma is not clear and may be due to increased Bax degradation activity and/ or decreased p53 transcriptional activity in these high-grade tumor cells.

Bax activation is a key step in the intrinsic apoptotic pathway which is triggered by DNA damage induced by chemo- and/or radiotherapies or spontaneous apoptosis in cancer cells. Lower levels of Bax protein are associated with decreased spontaneous apoptosis of cancer cells and poor prognosis in patients with cancer [40, 41]. In this study, we used both continuous and categorical analyses to determine the impact of Bax protein levels on clinical outcomes in patients with gliomas. Our data demonstrate that lower expression of Bax is significantly associated with higher grade glioma and shorter OS/RFS in patients with glioma. The median OS or RFS for this cohort of glioma patients is 28 or 23 months, respectively. With higher Bax expression, the median OS reaches to 45 and the median RFS to 50 months. This indicates that the levels of Bax protein play an important role in glioma cell spontaneous apoptosis vs. tumor growth. Therefore, targeting the anti-Bcl-2 family of proteins will have great potential in controlling disease progression of this cancer.

Radiotherapy and chemotherapy are the mainstay of treatment for gliomas but glioblastoma still remains incurable due to resistance to treatment-induced apoptosis. Lower Bax expression is one of the resistance mechanisms of glioma cells to chemo- or radiotherapy [9, 42]. Reliable methods for predicting treatment responses and clinical outcomes would be great beneficial to cure this disease. Patients with higher levels of Bax protein in glioma tissue showed significantly prolonged OS and RFS after radiotherapy or chemotherapy. This indicates that the levels of Bax protein is crucial for the responses to radiotherapy and chemotherapy. It was reported that treatment with $\mathrm{BH} 3$ mimetic ABT-737 releases the proapoptotic Bax protein from its binding partner $\mathrm{Bcl}-2$ and potently induces apoptotic cell death in glioblastoma cells in vitro and in vivo [43]. Combination of Bcl-2 inhibitors with radiotherapy/chemotherapy could overcome resistance of glioma cells to these treatment.

In summary, we demonstrate that Bax protein but not mRNA expression is decreased in glioblastoma tissue. Lower expression of Bax is associated with worse clinical outcome in patients with gliomas with radiotherapy and/ or chemotherapy. We therefore propose that Bax protein expression is a reliable and independent prognostic marker for predicting responses of radiotherapy/chemotherapy and clinical outcomes in patients with gliomas.

Acknowledgements This work was supported by the National Natural Science Foundation (NNSF) of China [81172109 and 81570191 to FT Liu, 81570194 to LJ]. The author would like to thank all patients with gliomas who kindly donated samples for this research.

Author contributions FTL and LJ conceived and designed this study. PGW, YTL, YP, and ZZG performed experiments and collected clinical information; YTL, XWG, FTL and LJ analyzed data. All authors contributed paper writing and proof reading.

\section{Compliance with ethical standards}

Conflict of interest There is none conflicts of interest to be declared.

Research involving human participants and/or animals Ethical approval for using human samples in this study was obtained from the local ethics committee.

Informed consent Patients gave verbal consent for the use of their tumor tissues for future investigations, which had been performed for many years at time of the initial diagnosis.

OpenAccess This article is distributed under the terms of the Creative Commons Attribution 4.0 International License (http://creativeco mmons.org/licenses/by/4.0/), which permits unrestricted use, distribution, and reproduction in any medium, provided you give appropriate credit to the original author(s) and the source, provide a link to the Creative Commons license, and indicate if changes were made. 


\section{References}

1. Ostrom QT, Gittleman H, Liao P, Vecchione-Koval T, Wolinsky Y, Kruchko C, Barnholtz-Sloan JS (2017) CBTRUS Statistical Report: Primary brain and other central nervous system tumors diagnosed in the United States in 2010-2014. Neuro Oncol 19:v1-v88. https://doi.org/10.1093/neuonc/nox158

2. Fuller GN, Scheithauer BW (2007) The 2007 Revised World Health Organization (WHO) classification of tumours of the central nervous system: newly codified entities. Brain Pathol (Zurich Switzerland) 17:304-307. https://doi.org/10.111 1/j.1750-3639.2007.00084.x

3. Diamandis P, Aldape K (2018) World Health Organization 2016 classification of central nervous system tumors. Neurol Clin 36:439-447. https://doi.org/10.1016/j.ncl.2018.04.003

4. Gilbert MR, Dignam JJ, Armstrong TS, Wefel JS, Blumenthal DT, Vogelbaum MA, Colman H, Chakravarti A, Pugh S, Won M, Jeraj R, Brown PD, Jaeckle KA, Schiff D, Stieber VW, Brachman DG, Werner-Wasik M, Tremont-Lukats IW, Sulman EP, Aldape KD, Curran WJ Jr, Mehta MP (2014) A randomized trial of bevacizumab for newly diagnosed glioblastoma. N Engl J Med 370:699-708. https://doi.org/10.1056/NEJMoa1308573

5. Gilbert MR, Wang M, Aldape KD, Stupp R, Hegi ME, Jaeckle KA, Armstrong TS, Wefel JS, Won M, Blumenthal DT, Mahajan A, Schultz CJ, Erridge S, Baumert B, Hopkins KI, Tzuk-Shina T, Brown PD, Chakravarti A, Curran WJ Jr, Mehta MP (2013) Dose-dense temozolomide for newly diagnosed glioblastoma: a randomized phase III clinical trial. J Clin Oncol 31:4085-4091. https://doi.org/10.1200/jco.2013.49.6968

6. Hadziahmetovic M, Shirai K, Chakravarti A (2011) Recent advancements in multimodality treatment of gliomas. Future Oncol (Lond Engl) 7:1169-1183. https://doi.org/10.2217/ fon.11.102

7. Hanahan D, Weinberg RA (2011) Hallmarks of cancer: the next generation. Cell 144:646-674. https://doi.org/10.1016/j. cell.2011.02.013

8. Valtorta S, Dico AL, Raccagni I, Gaglio D, Belloli S, Politi LS, Martelli C, Diceglie C, Bonanomi M, Ercoli G, Vaira V, Ottobrini L, Moresco RM (2017) Metformin and temozolomide, a synergic option to overcome resistance in glioblastoma multiforme models. Oncotarget 8:113090-113104. https://doi. org/10.18632/oncotarget.23028

9. Cartron PF, Juin P, Oliver L, Martin S, Meflah K, Vallette FM (2003) Nonredundant role of Bax and Bak in Bid-mediated apoptosis. Mol Cell Biol 23:4701-4712

10. Daniele S, Pietrobono D, Costa B, Giustiniano M, La Pietra V, Giacomelli C, La Regina G, Silvestri R, Taliani S, Trincavelli ML, Da Settimo F, Novellino E, Martini C, Marinelli L (2018) Bax activation blocks self-renewal and induces apoptosis of human glioblastoma stem cells. ACS Chem Neurosci 9:85-99. https://doi.org/10.1021/acschemneuro.7b00023

11. Vogelbaum MA, Tong JX, Perugu R, Gutmann DH, Rich KM (1999) Overexpression of bax in human glioma cell lines. J Neurosurg 91:483-489. https://doi.org/10.3171/jns.1999.91.3.0483

12. Friess H, Lu Z, Graber HU, Zimmermann A, Adler G, Korc M, Schmid RM, Buchler MW (1998) bax, but not bcl-2, influences the prognosis of human pancreatic cancer. Gut 43:414-421

13. Binder C, Marx D, Binder L, Schauer A, Hiddemann W (1996) Expression of $\mathrm{Bax}$ in relation to $\mathrm{Bcl}-2$ and other predictive parameters in breast cancer. Ann Oncol 7:129-133

14. Agrawal SG, Liu FT, Wiseman C, Shirali S, Liu H, Lillington D, Du MQ, Syndercombe-Court D, Newland AC, Gribben JG, Jia L (2008) Increased proteasomal degradation of Bax is a common feature of poor prognosis chronic lymphocytic leukemia. Blood
111:2790-2796. https://doi.org/10.1182/blood-2007-10-11046 0

15. Katkoori VR, Suarez-Cuervo C, Shanmugam C, Jhala NC, Callens T, Messiaen L, Posey J 3rd, Bumpers HL, Meleth S, Grizzle WE, Manne U (2010) Bax expression is a candidate prognostic and predictive marker of colorectal cancer. J Gastrointest Oncol 1:76-89. https://doi.org/10.3978/j.issn.2078-6891.2010.019

16. Jansson A, Sun XF (2002) Bax expression decreases significantly from primary tumor to metastasis in colorectal cancer. J Clin Oncol 20:811-816. https://doi.org/10.1200/jco.2002.20.3.811

17. Jeong SH, Lee HW, Han JH, Kang SY, Choi JH, Jung YM, Choi H, Oh YT, Park KJ, Hwang SC, Sheen SS, Oh YJ, Kim JH, Lim HY (2008) Low expression of Bax predicts poor prognosis in resected non-small cell lung cancer patients with non-squamous histology. Jpn J Clin Oncol 38:661-669. https://doi.org/10.1093/ jjco/hyn089

18. Skala E, Sitarek P, Toma M, Szemraj J, Radek M, NieborowskaSkorska M, Skorski T, Wysokinska H, Sliwinski T (2016) Inhibition of human glioma cell proliferation by altered Bax/Bcl-2-p53 expression and apoptosis induction by Rhaponticum carthamoides extracts from transformed and normal roots. J Pharm Pharmacol 68:1454-1464. https://doi.org/10.1111/jphp.12619

19. Li B, Dou QP (2000) Bax degradation by the ubiquitin/proteasome-dependent pathway: involvement in tumor survival and progression. Proc Natl Acad Sci USA 97:3850-3855. https://doi. org/10.1073/pnas.070047997

20. Daido S, Tamiya T, Ono Y, Terada K, Mizumatsu S, Ohmoto $\mathrm{T}$ (2001) Expression of Bcl-2, Bcl-x, and Bax proteins in astrocytomas in relation to patient survival. Brain Tumor Pathol 18:123-129

21. Strik H, Deininger M, Streffer J, Grote E, Wickboldt J, Dichgans J, Weller M, Meyermann R (1999) BCL-2 family protein expression in initial and recurrent glioblastomas: modulation by radiochemotherapy. J Neurol Neurosurg Psychiatry 67:763-768

22. Deininger MH, Weller M, Streffer J, Meyermann R (1999) Antiapoptotic Bcl-2 family protein expression increases with progression of oligodendroglioma. Cancer 86:1832-1839

23. Viotti J, Duplan E, Caillava C, Condat J, Goiran T, Giordano C, Marie Y, Idbaih A, Delattre JY, Honnorat J, Checler F, Alves da Costa C (2014) Glioma tumor grade correlates with parkin depletion in mutant p53-linked tumors and results from loss of function of p53 transcriptional activity. Oncogene 33:1764-1775. https:// doi.org/10.1038/onc.2013.124

24. Wang W, Cho HY, Rosenstein-Sisson R, Marin Ramos NI, Price R, Hurth K, Schonthal AH, Hofman FM, Chen TC (2017) Intratumoral delivery of bortezomib: impact on survival in an intracranial glioma tumor model. J Neurosurg: 1-6 https://doi. org/10.3171/2016.11.jns161212

25. (2008) Comprehensive genomic characterization defines human glioblastoma genes and core pathways. Nature 455: 1061-1068 https://doi.org/10.1038/nature07385

26. Brennan CW, Verhaak RG, McKenna A, Campos B, Noushmehr H, Salama SR, Zheng S, Chakravarty D, Sanborn JZ, Berman SH, Beroukhim R, Bernard B, Wu CJ, Genovese G, Shmulevich I, Barnholtz-Sloan J, Zou L, Vegesna R, Shukla SA, Ciriello G, Yung WK, Zhang W, Sougnez C, Mikkelsen T, Aldape K, Bigner DD, Van Meir EG, Prados M, Sloan A, Black KL, Eschbacher J, Finocchiaro G, Friedman W, Andrews DW, Guha A, Iacocca M, O'Neill BP, Foltz G, Myers J, Weisenberger DJ, Penny R, Kucherlapati R, Perou CM, Hayes DN, Gibbs R, Marra M, Mills GB, Lander E, Spellman P, Wilson R, Sander C, Weinstein J, Meyerson M, Gabriel S, Laird PW, Haussler D, Getz G, Chin L (2013) The somatic genomic landscape of glioblastoma. Cell 155:462-477. https://doi.org/10.1016/j.cell.2013.09.034

27. Wen PY, Macdonald DR, Reardon DA, Cloughesy TF, Sorensen AG, Galanis E, Degroot J, Wick W, Gilbert MR, Lassman AB, 
Tsien C, Mikkelsen T, Wong ET, Chamberlain MC, Stupp R, Lamborn KR, Vogelbaum MA, van den Bent MJ, Chang SM (2010) Updated response assessment criteria for high-grade gliomas: response assessment in neuro-oncology working group. J Clin Oncol 28:1963-1972. https://doi.org/10.1200/jco.2009.26.3541

28. van West SE, de Bruin HG, van de Langerijt B, Swaak-Kragten AT, van den Bent MJ, Taal W (2017) Incidence of pseudoprogression in low-grade gliomas treated with radiotherapy. Neuro Oncol 19:719-725. https://doi.org/10.1093/neuonc/now194

29. Wang X, Ren H, Zhao T, Chen J, Sun W, Sun Y, Ma W, Wang J, Gao C, Gao S, Lang M, Jia L, Hao J (2014) Stem cell factor is a novel independent prognostic biomarker for hepatocellular carcinoma after curative resection. Carcinogenesis 35:2283-2290. https://doi.org/10.1093/carcin/bgu162

30. Camp RL, Dolled-Filhart M, Rimm DL (2004) X-tile: a new bioinformatics tool for biomarker assessment and outcome-based cut-point optimization. Clin Cancer Res 10:7252-7259. https:// doi.org/10.1158/1078-0432.ccr-04-0713

31. Greaves P, Clear A, Coutinho R, Wilson A, Matthews J, Owen A, Shanyinde M, Lister TA, Calaminici M, Gribben JG (2013) Expression of FOXP3, CD68, and CD20 at diagnosis in the microenvironment of classical Hodgkin lymphoma is predictive of outcome. J Clin Oncol 31:256-262. https://doi.org/10.1200/ jco.2011.39.9881

32. Jia L, Clear A, Liu FT, Matthews J, Uddin N, McCarthy A, Hoxha E, Durance C, Iqbal S, Gribben JG (2014) Extracellular HMGB1 promotes differentiation of nurse-like cells in chronic lymphocytic leukemia. Blood 123:1709-1719. https://doi.org/10.1182/blood -2013-10-529610

33. Nonnenmacher L, Westhoff MA, Fulda S, Karpel-Massler G, Halatsch ME, Engelke J, Simmet T, Corbacioglu S, Debatin KM (2015) RIST: a potent new combination therapy for glioblastoma. Int J Cancer 136:E173-E187. https://doi.org/10.1002/ijc.29138

34. Shaw EG, Wang M, Coons SW, Brachman DG, Buckner JC, Stelzer KJ, Barger GR, Brown PD, Gilbert MR, Mehta MP (2012) Randomized trial of radiation therapy plus procarbazine, lomustine, and vincristine chemotherapy for supratentorial adult low-grade glioma: initial results of RTOG 9802. J Clin Oncol 30:3065-3070. https://doi.org/10.1200/jco.2011.35.8598

35. Stupp R, Hegi ME, Mason WP, van den Bent MJ, Taphoorn MJ, Janzer RC, Ludwin SK, Allgeier A, Fisher B, Belanger K, Hau P, Brandes AA, Gijtenbeek J, Marosi C, Vecht CJ, Mokhtari K,
Wesseling P, Villa S, Eisenhauer E, Gorlia T, Weller M, Lacombe D, Cairncross JG, Mirimanoff RO (2009) Effects of radiotherapy with concomitant and adjuvant temozolomide versus radiotherapy alone on survival in glioblastoma in a randomised phase III study: 5-year analysis of the EORTC-NCIC trial. Lancet Oncol 10:459-466. https://doi.org/10.1016/s1470-2045(09)70025-7

36. Wen PY, Reardon DA (2016) Neuro-oncology in 2015: Progress in glioma diagnosis, classification and treatment. Nat Rev Neurol 12:69-70. https://doi.org/10.1038/nrneurol.2015.242

37. Bose P, Klimowicz AC, Kornaga E, Petrillo SK, Matthews TW, Chandarana S, Magliocco AM, Brockton NT, Dort JC (2012) Bax expression measured by AQUAnalysis is an independent prognostic marker in oral squamous cell carcinoma. BMC Cancer 12:332. https://doi.org/10.1186/1471-2407-12-332

38. Sohn SK, Jung JT, Kim DH, Kim JG, Kwak EK, Park T, Shin DG, Sohn KR, Lee KB (2003) Prognostic significance of bcl-2, bax, and p53 expression in diffuse large B-cell lymphoma. Am J Hematol 73:101-107. https://doi.org/10.1002/ajh.10333

39. Schuyer M, van der Burg ME, Henzen-Logmans SC, Fieret JH, Klijn JG, Look MP, Foekens JA, Stoter G, Berns EM (2001) Reduced expression of BAX is associated with poor prognosis in patients with epithelial ovarian cancer: a multifactorial analysis of TP53, p21, BAX and BCL-2. Br J Cancer 85:1359-1367. https ://doi.org/10.1054/bjoc.2001.2101

40. Xie X, Clausen OP, De Angelis P, Boysen M (1999) The prognostic value of spontaneous apoptosis, Bax, Bcl-2, and p53 in oral squamous cell carcinoma of the tongue. Cancer 86:913-920

41. Del Poeta G, Venditti A, Del Principe MI, Maurillo L, Buccisano F, Tamburini A, Cox MC, Franchi A, Bruno A, Mazzone C, Panetta P, Suppo G, Masi M, Amadori S (2003) Amount of spontaneous apoptosis detected by $\mathrm{Bax} / \mathrm{Bcl}-2$ ratio predicts outcome in acute myeloid leukemia (AML). Blood 101:2125-2131. https:// doi.org/10.1182/blood-2002-06-1714

42. Streffer JR, Rimner A, Rieger J, Naumann U, Rodemann HP, Weller M (2002) BCL-2 family proteins modulate radiosensitivity in human malignant glioma cells. J Neurooncol 56:43-49

43. Tagscherer KE, Fassl A, Campos B, Farhadi M, Kraemer A, Bock BC, Macher-Goeppinger S, Radlwimmer B, Wiestler OD, HeroldMende C, Roth W (2008) Apoptosis-based treatment of glioblastomas with ABT-737, a novel small molecule inhibitor of Bcl-2 family proteins. Oncogene 27:6646-6656. https://doi.org/10.1038/ onc. 2008.259 